\title{
Manyetik Aktif Karbon/ZnO Kompozitinin Sentezlenmesi ve Boyar Madde Giderimi Üzerine Denge ve Kinetik Uygulaması
}

\author{
Eda Çiv ${ }^{1}$, Atakan Toprak ${ }^{2 *}$, Kadriye Bozgeyik ${ }^{3}$ \\ ${ }^{1}$ Zonguldak Bülent Ecevit Üniversitesi, Nanoteknoloji Mühendisliği Bölümü, Zonguldak, Türkiye (ORCID: 0000-0003-4704-1769) \\ 2 Zonguldak Bülent Ecevit Üniversitesi, Kimya ve Kimyasal Proses Teknolojisi Bölümü, Zonguldak, Türkiye (ORCID: 0000-0003-0008-1456) \\ ${ }^{3}$ Zonguldak Bülent Ecevit Üniversitesi, Kimya Bölümü, Zonguldak, Türkiye (ORCID: 0000-0002-1958-2974)
}

(İlk Geliş Tarihi 20 Ocak 2020 ve Kabul Tarihi 16 Mart 2020)

(DOI: 10.31590/ejosat.673884)

ATIF/REFERENCE: Çiv, E, Toprak, A. \& Bozgeyik, K. (2020). Manyetik Aktif Karbon/ZnO Kompozitinin Sentezlenmesi ve Boyar Madde Giderimi Üzerine Denge ve Kinetik Uygulaması. Avrupa Bilim ve Teknoloji Dergisi, (18), 552-561.

$\ddot{O} \mathbf{z}$

Bu çalışmamızda, atık kauçuktan kimyasal aktivasyonu ile aktif karbon, ardından da tek basamakta termal yöntem ile manyetik aktif karbon/ZnO nanokompozitleri sentezlenmiştir. Sentezlenen kompozitlerin sulu çözeltide boyar madde adsorpsiyon denge ve kinetik çalışmaları incelenmiştir. Nanokompozitlerin fizikokimyasal özellikleri ve karakterizasyonu azot adsorpsiyonu, SEM-EDX ve XRD ile belirlenmiş̧ir. Beş farklı manyetik aktif karbon/ZnO nanokompozitlerinin sulu çözeltide Malahit yeşili (MG) için Langmuir ve Freunlich izoterm modelinde uygulanarak adsorpsiyon kapasiteleri belirlenmiştir. Elde edilen sonuçlara göre en yüksek adsorpsiyon kapasitesi hekzametilen tetramin (HMTA) ve $\mathrm{ZnCl}_{2}$ ile üretilen manyetik nanokompozitte $502.5 \mathrm{mg} / \mathrm{g}$ olarak bulunmuş̧ur. Adsorpsiyon kinetiği için birinci ve ikinci mertebe kinetik modeller kullanılmıştır. Yapılan kinetik çalışmalarda beş nanokompozitin de birinci dereceden hız sabitine uyduğu bulunmuştur.

\section{Synthesis of Magnetic Activated Carbon / ZnO Composite and Equilibrium and Kinetics Application on the Removal of Dyestuff}

\begin{abstract}
In this study, activated carbon was prepared by chemical activation from waste rubber, and then magnetic activated carbon/ZnO nanocomposites were synthesized by single step thermal method. The equilibrium and kinetic study of dye adsorption in aqueous solution of synthesized composites was investigated. Physicochemical properties and characterization of nanocomposites were determined by nitrogen adsorption, SEM-EDX and XRD. Adsorption capacities of five different magnetic activated carbon / ZnO nanocomposites were calculated by applying Langmuir and Freundlich isotherm models for Malachite green (MG) in aqueous solution. According to the results, the highest adsorption capacity was found to be $502.5 \mathrm{mg} / \mathrm{g}$ in the magnetic nanocomposite produced by hexamethylene tetramine (HMTA) and $\mathrm{ZnCl}_{2}$. First and second order kinetic models were used for adsorption kinetics. Accordingly, five nanocomposites were found to match the pseudo-first-order kinetics.
\end{abstract}

Keywords: Activated carbon, Magnetic composite, ZnO, Dye removal, Kinetic.

\footnotetext{
${ }^{*}$ Sorumlu Yazar: Zonguldak Bülent Ecevit Üniversitesi, Kimya ve Kimyasal Proses Teknolojisi Bölümü, Zonguldak, Türkiye, ORCID: 0000-0003-0008-1456, atakantoprak2@hotmail.com
} 


\section{Giriş}

Dünyada yıllık 700.000 ton boyar madde üretilirken bu boyar maddelerin 100.000'den fazla farklı çeşidi bulunmaktadır. Yani her yı1 700.000 ton boyar madde su kaynaklarını kirletmektedir (Erdoğan, 2017). Atık suların doğal su kaynaklarına karışması ya da yer altı sularına ulaşması sonucu bu kirlilik çığ gibi büyümektedir. Günümüzde verimli su kullanımı ve geri dönüşüm gibi konular her geçen gün önem kazanmaktadır. Atık su geri dönüşümünde boyar maddelerin giderimi önemli bir yer tutmaktadır. Boyar maddelerin kullanımı sanayinin çok çeşitli alanlarından sağlık endüstrisine kadar çok geniş bir alanı kapsamaktadır. Bu geniş kapsamlı kullanımın bir sonucu olarak da geride kalan boyar madde atıkları doğa ve canlı hayatı için büyük tehlike arz etmektedir. Boyaların kanserojen etkisi yanında sulu ortamda artan azo boyar maddeler güneş 1şı ğının deniz tabanına erişimini engelleyerek suda yaşayan bitki ve canlı dengesinde olumsuz yönde etkilemektedir (Aluigi ve ark., 2014). Sulu ortamlardan boyar maddelerin uzaklaştırılması için literatürde birçok farklı yöntem kullanılmaktadır. Adsorpsiyon en çok ilgi gören yöntemlerin başından gelmektedir. Adsorpsiyonda yaygın olarak kullanılan adsorbentlerin başında aktif karbonlar, polimerik malzemeler ve zeolit gibi ürünler gelmektedir (Kopaç ve ark., 2016; Toprak ve Bozgeyik, 2017; Yener ve ark., 2006). Adsorpsiyonda, diğer adsorbentlere göre aktif karbonun ilgi çekici olmasının nedenleri arasında üretiminin kolay olması, üretim maliyetinin düşük ve geleneksel yöntemler ile üretilebilmesi büyük rol oynamaktadır. Adsorbentlerin, adsorpsiyon işlemi tamamlandıktan sonra sulu sistemden uzaklaştırılması ayrılması ve yenilenmesi gerekmektedir. Ayrılan adsorbentin içerisindeki boyar maddenin uzaklaştırılarak tekrar sisteme dahil edilmesi birim üründen daha fazla verim alınmasını sağlamaktadır. Ancak, ayırma prosesi normalde santrifüjleme veya filtrasyon gibi karmaşık sistemleri içermektedir (Do ve ark., 2011; Fuertes ve Tartaj, 2006). Buna ek olarak, kirleticilerin sudan adsorpsiyon oranını arttırmak için, aktif karbon ve toz halindeki aktif karbon (PAC) gibi küçük toz parçacıklarının mikro-nano boyutları genellikle kullanılmaktadır. Bu durumun ne yazık ki, filtrelerin tıkanmasına, proseste aksaklıklara veya malzeme kaybına neden olmaktadır. Adsorbentlerin sistemden uzaklaştırma problemini çözmek adına son zamanlarda araştırmalar manyetik olarak ayrılabilir malzemeler üretilmesine odaklanmıştır. Bu sayede ayırma işlemi, manyetik bir alan uygulanarak büyük ölçüde basitleştirilmektedir (Wang ve ark., 2008; Yang ve ark., 2008).

Katyonik boyar madde olan malahit yeşili, kumaş yüzeyi ve plastik yüzeylerin renklendirilmesinde de kullanılan dispers boyar maddeler kategorisinde yer almaktadır. Dispers boyar maddeler boyamada meydana getirdikleri özellikler ile bu adı alırlar. Dispers boyar maddeler içerdikleri fonksiyonel gruplara göre kinaftalon, antrakinon, noftakinon ve azo boyar madde olarak isimlendirilir (Akkurt ve ark., 2005).

Bu çalışmada, atık kauçuktan kimyasal aktivasyon ve devamında termal yöntem ile gözenekli yapıya sahip manyetik özellikte kompozitler üretilmiştir. Üretilen farklı özellikteki manyetik aktif karbon/ZnO kompozitlerinin, sulu ortamda MG gideriminin kinetik ve denge uygulamaları yapılarak kapasiteleri belirlenmiştir.

\section{Materyal ve Metot}

\subsection{Aktif Karbon Üretimi}

Aktif karbon üretmek amacıyla, Zonguldak bölgesinde faaliyet gösteren kauçuk fabrikasının atık departmanından temin edilen kauçuk, saf su ile yıkama işlemi yapılarak yüzeydeki kirleticiler uzaklaştırılmıştır. Ardından 300-500 $\mu$ m aralığında öğütülen kauçuk fırında $25^{\circ} \mathrm{C} / \mathrm{dak}$ artış hızında $800^{\circ} \mathrm{C}$ 'de 1 saat tutularak karbonizasyon işlemi uygulanarak karbonize kauçuk (KK) elde edilmiştir (Kopac ve Toprak, 2007). KK numunesindeki inorganik ve kirletici maddelerin yapıdan uzaklaştırılması amacıyla, \% 7 'lik $\mathrm{H}_{2} \mathrm{O}_{2}$ ile $50{ }^{\circ} \mathrm{C}$ 'de geri soğutucu altında $750 \mathrm{rpm}$ 'de 5 saat karıştırılarak $\mathrm{KK}-\mathrm{H}_{2} \mathrm{O}_{2}$ üretilmiştir. KOH'in $\mathrm{KK}-\mathrm{H}_{2} \mathrm{O}_{2}$ ile ağırlıkça 4:1 oranında sulu çözeltisi $70^{\circ} \mathrm{C}$ 'de 1 saat karıştırmıştır $(750 \mathrm{rpm})$ ve $60^{\circ} \mathrm{C}$ 'de 1 saat sonikasyon uygulaması gerçekleştirilmiştir. Etüvde 90 ${ }^{\circ} \mathrm{C}$ 'de kurutma işlemleri uygulanarak sulu kısım uzaklaştırılmıştır. Son aşamada, kimyasal aktivasyon işlemi için karışım kapaklı kroze içerisine alınarak firında $20{ }^{\circ} \mathrm{C} / \mathrm{dak}$ artış hızında $800{ }^{\circ} \mathrm{C}$ 'de 1 saat tutularak aktif karbon (AK) elde edilmiştir

\subsection{Manyetik AKZnO (MAKZnO) Sentezi}

Tablo 1'de manyetik özelliğe sahip AKZnO kompozitinin kullanılan ağırlıkça oranları aşağıdaki tabloda verilmiştir. 
Tablo 1. MAKZnO Sentezinde Kullanilan Kimyasallar ve Oranlart

\begin{tabular}{|ccc|cccc|}
\hline Kompozit & $\mathbf{A K}$ & $\mathrm{ZnCl}_{2}$ & $\mathbf{Z n}\left(\mathrm{NO}_{3}\right)_{2} .6 \mathbf{H}_{2} \mathbf{O}$ & $\mathbf{F e}\left(\mathrm{NO}_{3}\right)_{3} .9 \mathrm{H}_{2} \mathbf{O}$ & $\mathrm{NaOH}$ & HDTMA \\
\hline MAKZnO 1 & 1 & 1 & & 1 & $1 / 3$ & \\
MAKZnO 2 & 1 & 1 & 2 & $1 / 3$ & \\
MAKZnO 3 & 1 & 1 & 1 & 2 & & $1 / 3$ \\
MAKZnO 4 & 1 & & & 2 & $1 / 3$ \\
MAKZnO 5 & 1 & 2 & & 2 & $1 / 3$ \\
\hline
\end{tabular}

Tablo 1'de belirtilen oranlar alınarak nanokompozit üretimi için $\mathrm{AK}, \mathrm{Zn}\left(\mathrm{NO}_{3}\right)_{2} \cdot 6 \mathrm{H}_{2} \mathrm{O}, \mathrm{Fe}\left(\mathrm{NO}_{3}\right)_{3} .9 \mathrm{H}_{2} \mathrm{O}$ ve $\mathrm{NaOH}$ ya da Hekzametilen tetramin (HMTA) tartılarak etanolde çözüldü. AK ve $\mathrm{Zn}\left(\mathrm{NO}_{3}\right)_{2} \cdot 6 \mathrm{H}_{2} \mathrm{O}$ çözeltisi manyetik karıştırıcıda 10 dakika (dak) karıştırıldıktan sonra içerisine $\mathrm{Fe}\left(\mathrm{NO}_{3}\right)_{3} .9 \mathrm{H}_{2} \mathrm{O}$ çözeltisi yavaşça eklendi ve 10 dak daha karıştıııldı. Son olarak hazırlanmış olan $\mathrm{NaOH}$ ya da HMTA çözeltisi damla damla karışıma eklendi. $\mathrm{NaOH}$ ya da HMTA ilavesiyle karışımda çökelti oluşmaya başladı. Karışım $90^{\circ} \mathrm{C}^{\prime}$ de 1 saat (sa) geri soğutucuda karıştırıldı ve $95^{\circ} \mathrm{C}$ 'deki etüvde çözücü tamamen uçana kadar bırakıldı. Etüvden alınan kuru haldeki çökelek kapaklı krozeye alınarak firında $30{ }^{\circ} \mathrm{C} /$ dak artış hızında $750{ }^{\circ} \mathrm{C}$ ye çıkarıldı ve burada 20 dak tutuldu. Elde edilen ürün sıcak saf su ile defalarca yıkama işlemlerinden geçirildikten sonra etüvde kurutuldu. Bu şekilde manyetik (M) özelliğe sahip AKZnO kompoziti (MAKZnO) elde edildi. Şekil 1'de MAK/ZnO nanokompozit'in üretim şemasi gösterilmektedir.

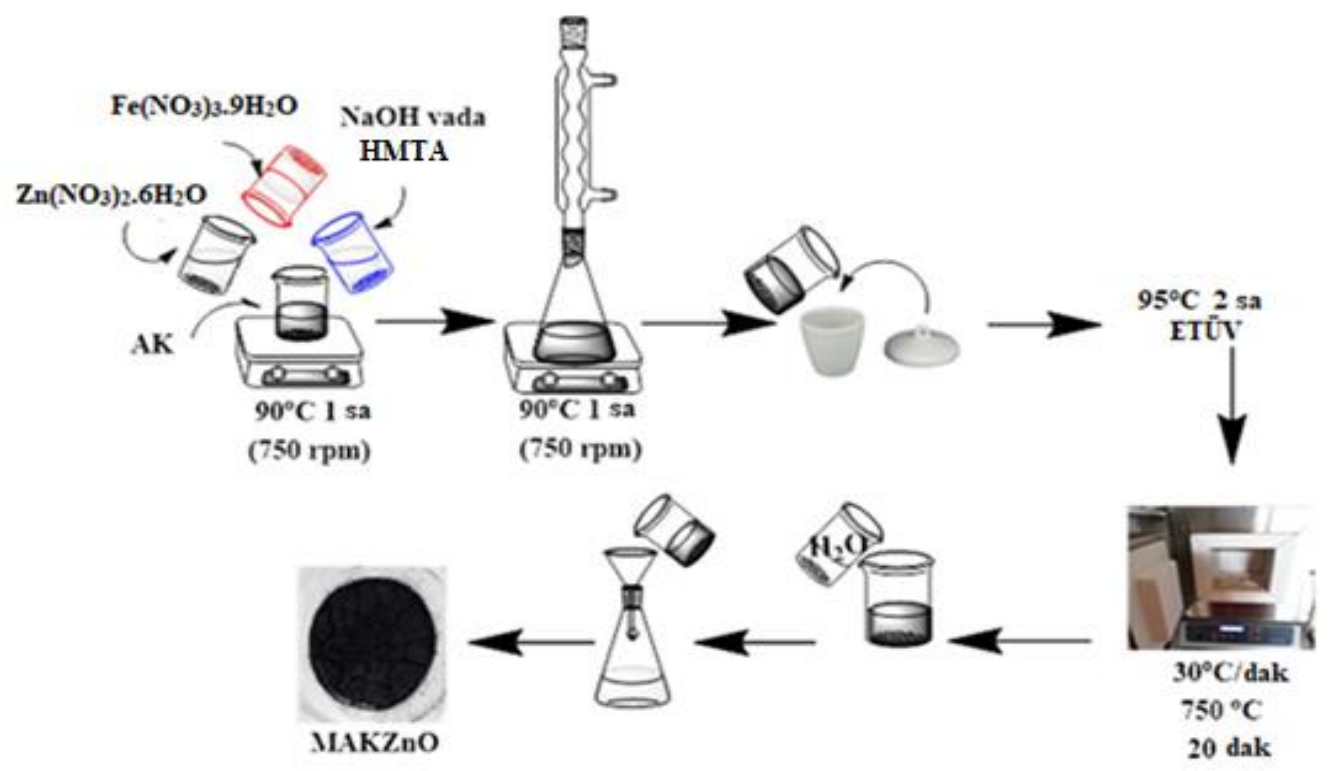

Şekil 1. MAKZnO nanokompozit üretim şeması.

\subsection{Adsorpsiyon Kinetiği Deney Prosedürü}

MAKZnO nanokompozitlerin adsorpsiyon kinetiğinin ve kapasitesinin incelenmesi için, MG'nin sulu ortamdaki adsorpsiyon deneyleri gerçekleştirilmiştir. Deneylerde $20 \mathrm{mg} / \mathrm{L}^{\prime}$ lik MG'den $50 \mathrm{ml}$ alınarak farklı miktarlardaki (2-10 mg) adsorbentler ile oda sıcaklı̆ğında karıştırılmıştır. MG adsorbent karışımından belirli zaman aralıklarında örnek alınarak UV-Vis cihazında $615 \mathrm{~nm}$ dalga boyunda adsorbans değişimleri incelenmiştir. MAKZnO 1-5 örneklerindeki elde edilen zamana karşı derişim değerleri Langmuir ve Freundlich izoterm modellerine uygulanarak adsorpsiyon kapasiteleri belirlenmiştir.

\section{Araştırma Sonuçları ve Tartışma}

\subsection{MAKZnO Karakterizasyonu}

Şekil 2-6'da MAK/ZnO 1-5'lerin Taramalı Elektron Mikroskobu-Enerji yayılımlı X-Işını Analizi (SEM-EDX) ile yüzey morfolojisi ve elementlerin ağırlıkça yüzdeleri verilmiş̧tir. Şekil 2-6'daki SEM resimlerinin hepsinde AK'nun yüzeyinde Fe ve 
Zn'nun oksitleri şeklinde biriktiği gözlenmiştir. Bu kümelenmeler düzensiz ve yüzeyde farklı boyutlarda gözenekler ve oyuklar oluşturmuştur.

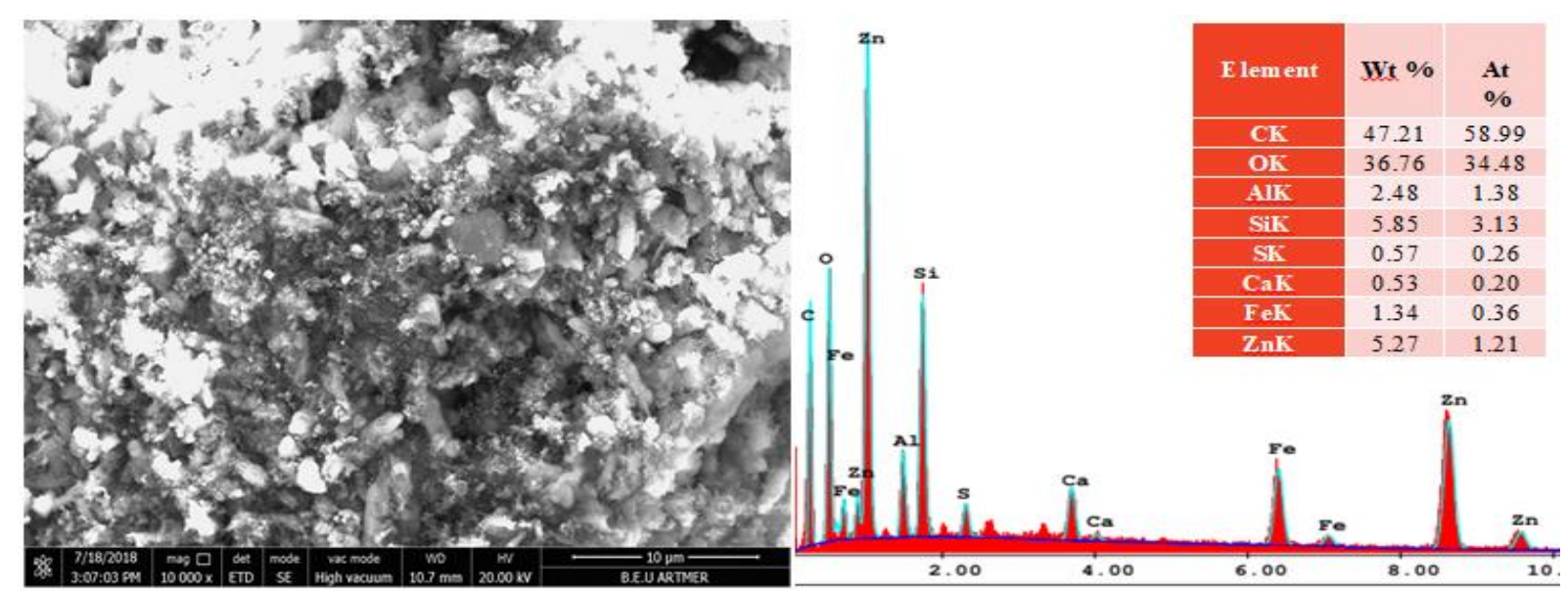

Şekil 2. MAKZnO 1'in SEM görüntüsü ve EDX analizi

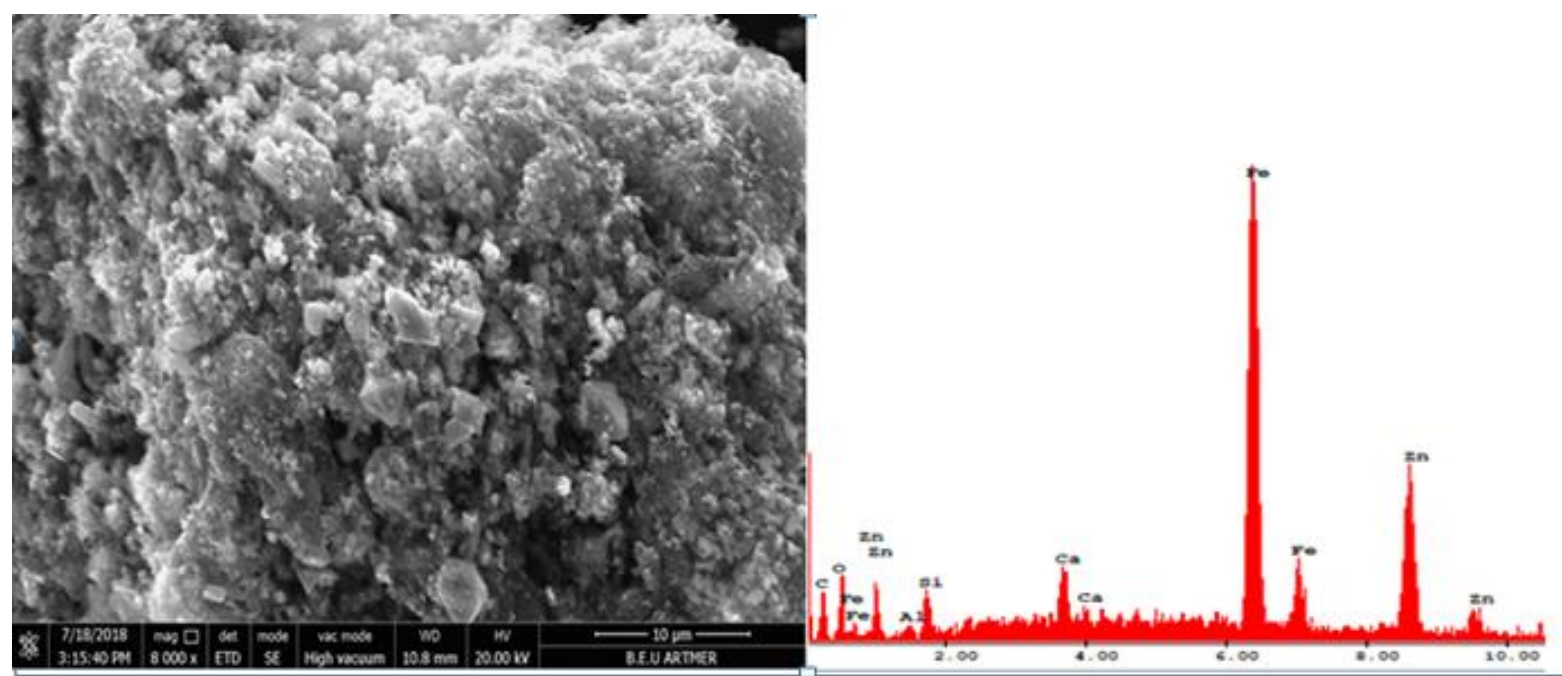

Şekil 3. MAKZnO2'nin SEM görüntüsü ve EDX analizi
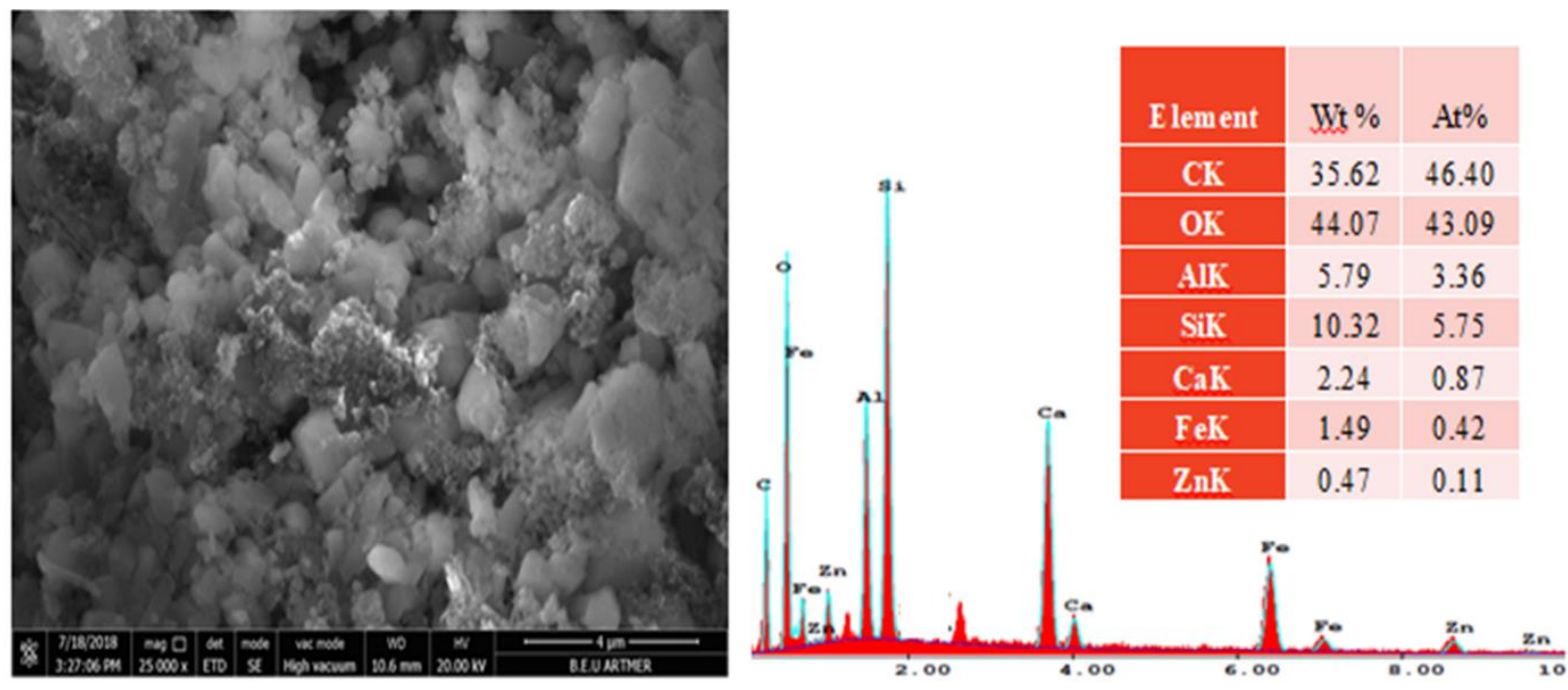

Şekil 4. MAKZnO 3’ün SEM görüntüsü ve EDX analizi 


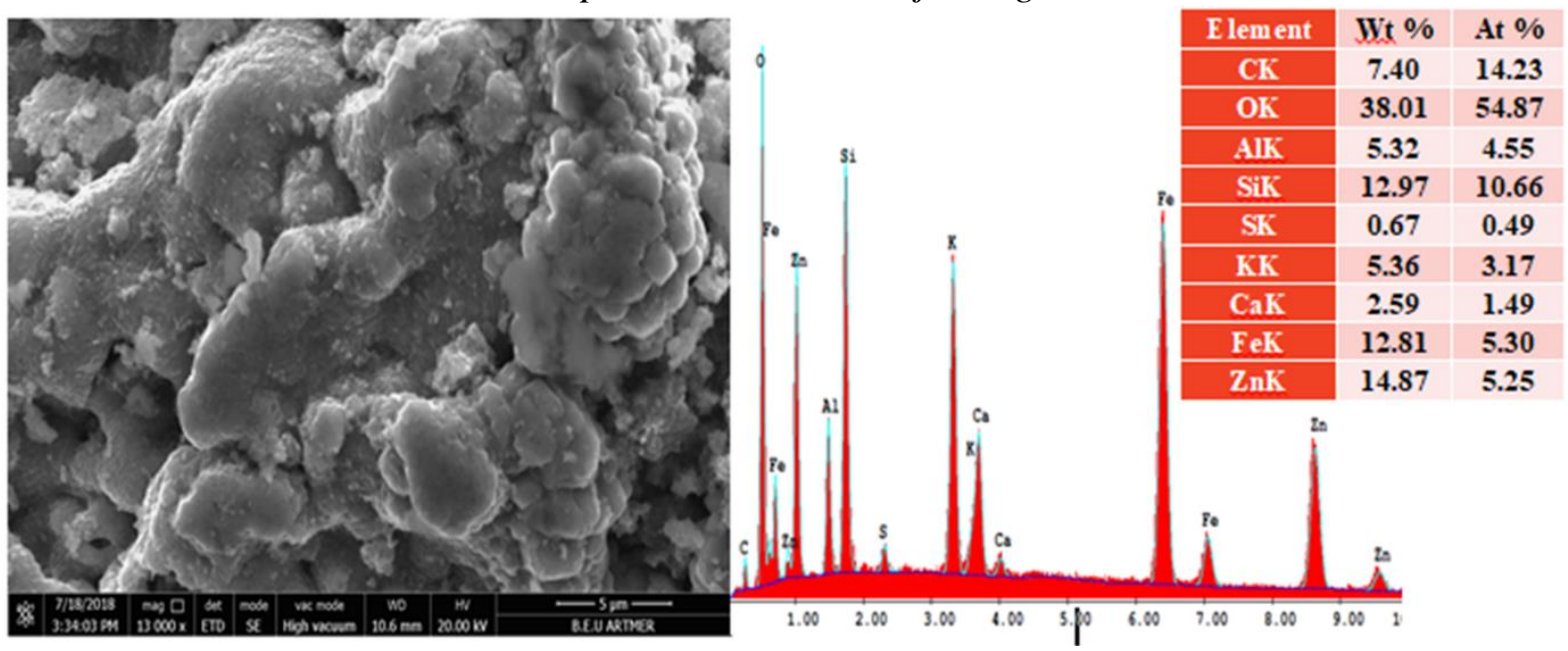

Şekil 5. MAKZnO 4'ün SEM görüntüsü ve EDX analizi

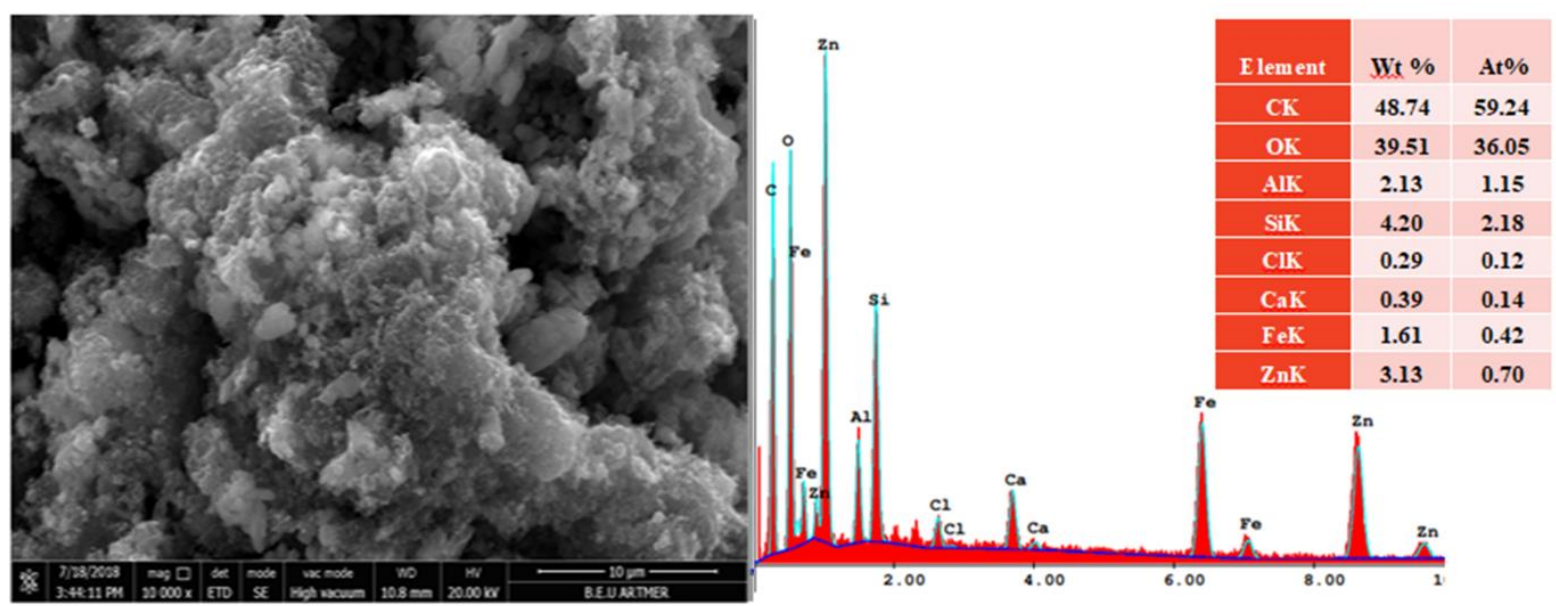

Şekil 6. MAKZnO 5 'in SEM görüntüsü ve EDX analizi

Şekil 7'de AK'nun $\mathrm{ZnCl}_{2}$ ve $\mathrm{Fe}\left(\mathrm{NO}_{3}\right)_{3} .9 \mathrm{H}_{2} \mathrm{O}$ ile eşit oranlarda ve bazik ortam sağlaması için $\mathrm{NaOH}$ kullanılarak üretilen MAKZnO 1'in X-Işını Kırınım yöntemi (XRD) pikleri görülmektedir. MAKZnO 1 kompozitinde XRD piklerinden yararlanılarak; $\mathrm{Fe}_{3} \mathrm{O}_{4}$ (Magnetit), $\mathrm{Fe}_{2} \mathrm{O}_{3}$ (Hematit), $\mathrm{ZnO}$ kristalleri ve metalik $\mathrm{Fe}$ olduğu belirlenmiştir. $\mathrm{Fe}_{3} \mathrm{O}_{4}$ 'ün 20 = 35,5' deki pikinin (311) yönelimli kübik yapıda olduğunu göstermektedir. $25.5^{\circ}$ ve $34^{\circ}$ 'deki pikler ise $\mathrm{Fe}_{2} \mathrm{O}_{3}$ 'ün karakteristik (012) ve (104) düzelmelerinin indeksidir. ZnO'nun $2 \theta=31.5^{\circ}$ 'deki karakteristik (100) düzlemli piki kompozitte ZnO kristallerinin oluşumunu ispatlamaktadır. Ayrıca MAKZnO 1'in Debye-Scherrer eşitliği (Chaki ve ark., 2015), yukarıda belirlenen karakteristik XRD piklerine uygulayarak $\mathrm{Fe}_{3} \mathrm{O}_{4}, \mathrm{Fe}_{2} \mathrm{O}_{3}$ ve $\mathrm{ZnO}$ 'nun ortalama kristal boyutları hesaplanmıştır. Buna göre; $\mathrm{ZnO}, \mathrm{Fe}_{3} \mathrm{O}_{4}$ ve $\mathrm{Fe}_{2} \mathrm{O}_{3}$ 'ün ortalama kristal boyutları sırasıyla, $48.16,42.56$ ve $55.45 \mathrm{~nm}$ olarak bulunmuştur. 


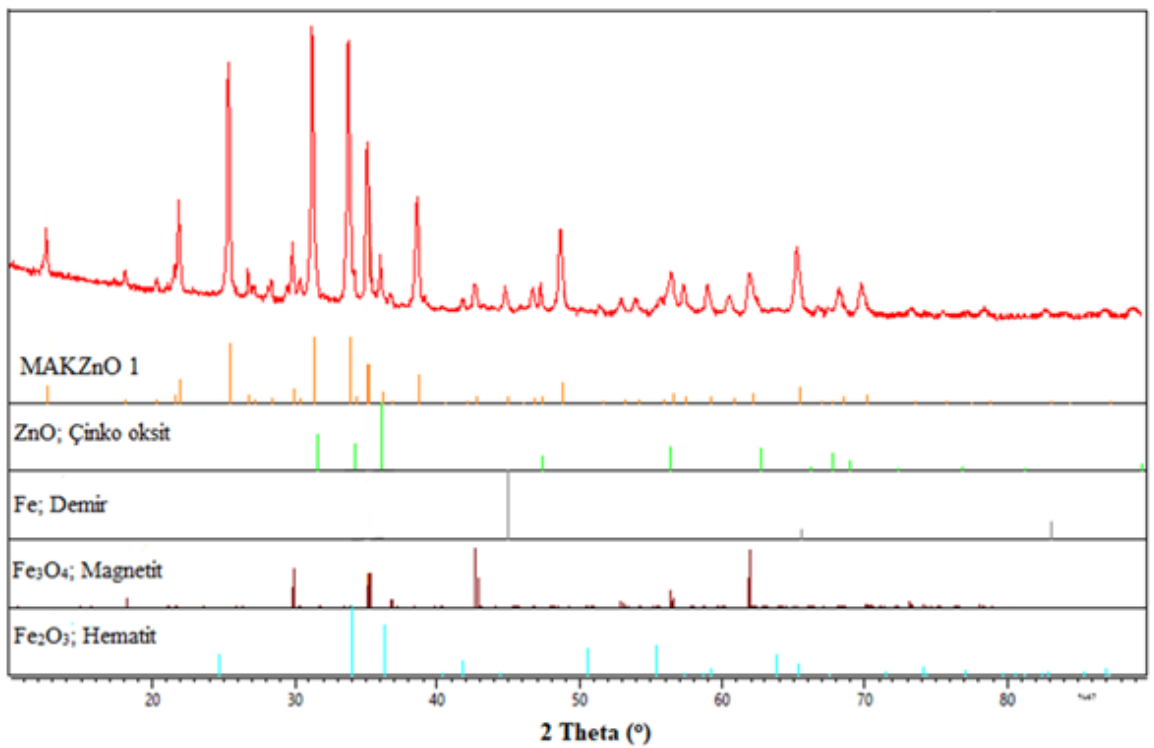

Şekil 7. MAKZnO 1 XRD spektrumu

Şekil 8'de MAKZnO 2'in XRD pikleri görülmektedir. MAKZnO 2, MAKZnO 1'e göre sadece Fe( $\left.\mathrm{NO}_{3}\right)_{3} .9 \mathrm{H}_{2} \mathrm{O}$ oranın 2 katına çıkartılarak üretilmiştir. MAKZnO 2'nin XRD piklerinden de $\mathrm{Fe}_{3} \mathrm{O}_{4}$ (Magnetit), $\mathrm{Fe}_{2} \mathrm{O}_{3}$ (Hematit), ZnO kristalleri ve metalik Fe olduğu belirlenmiştir. MAK/ZnO 2'nin Debye-Scherrer eşitliğinden yararlanılarak ortalama gözenek boyutları; $\mathrm{Fe}_{3} \mathrm{O}_{4}$ 'ün $2 \theta=$ $35,5^{\circ}$ 'deki pikinden (311) bulunan ortalama kristal boyutu 37.83 nm'dir. $\mathrm{Fe}_{2} \mathrm{O}_{3}$ 'ün karakteristik $25.5^{\circ}$ 'deki (012) yönelimli pikinden hesaplanan ortalama kristal boyutu $66.54 \mathrm{~nm}$ ve ZnO'nun $2 \theta=31.5^{\circ}$ 'deki karakteristik (100) düzlemli pikinden hesaplanan ortalama kristal boyutu ise $56.18 \mathrm{~nm}$ olarak bulunmuştur.

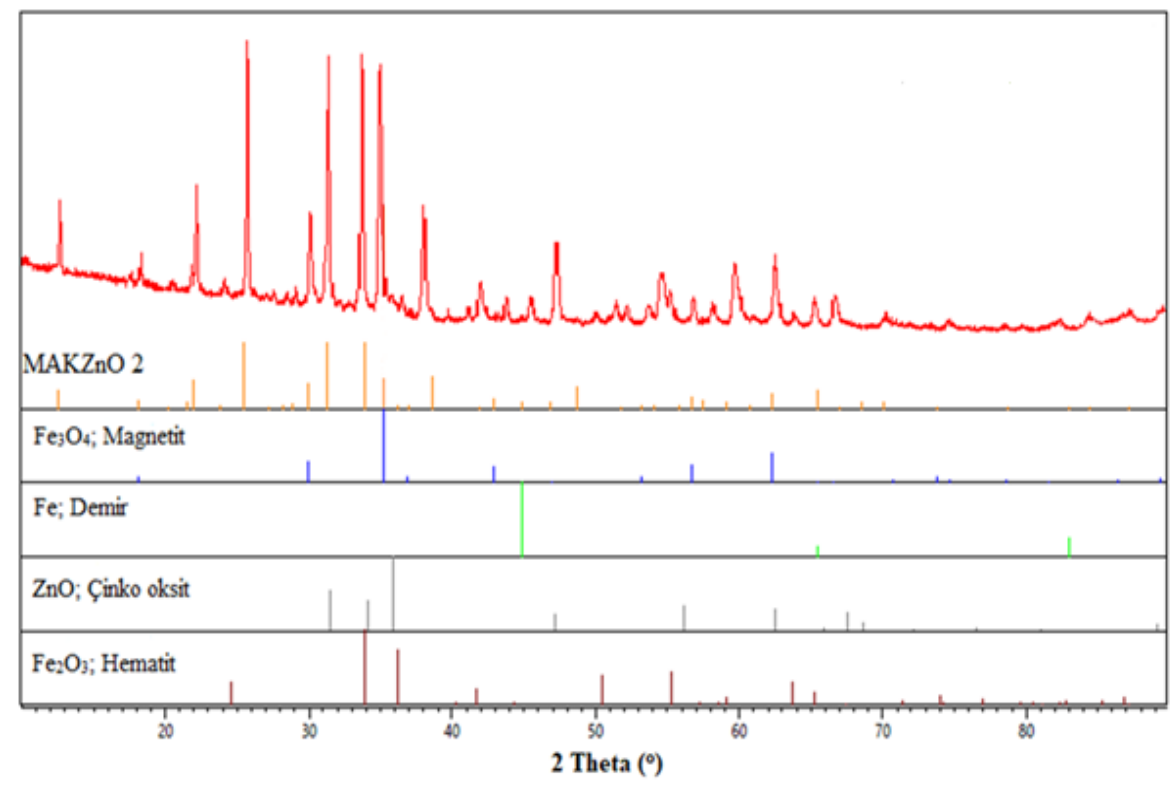

Şekil 8. MAKZnO 2 XRD spektrumu

Şekil 9' da MAKZnO 3'ün XRD pikleri görülmektedir. MAKZnO 3, MAKZnO 2'ye göre sadece bazik ortam sağlayıcısı olarak $\mathrm{NaOH}$ yerine HMTA kullanılarak üretilmiştir. MAKZnO 3' de de $\mathrm{Fe}_{3} \mathrm{O}_{4}$ (Magnetit), $\mathrm{Fe}_{2} \mathrm{O}_{3}$ (Hematit), ZnO kristalleri ve metalik Fe olduğu XRD piklerinde görülmüştür. MAKZnO 3'deki $\mathrm{ZnO}$ (100), $\mathrm{Fe}_{3} \mathrm{O}_{4}$ (311) ve $\mathrm{Fe}_{2} \mathrm{O}_{3}$ 'ün (012) hesaplanan ortalama kristal boyutları sırasıyla, 48.14, 48.65 ve $66.55 \mathrm{~nm}$ olarak bulunmuştur. 


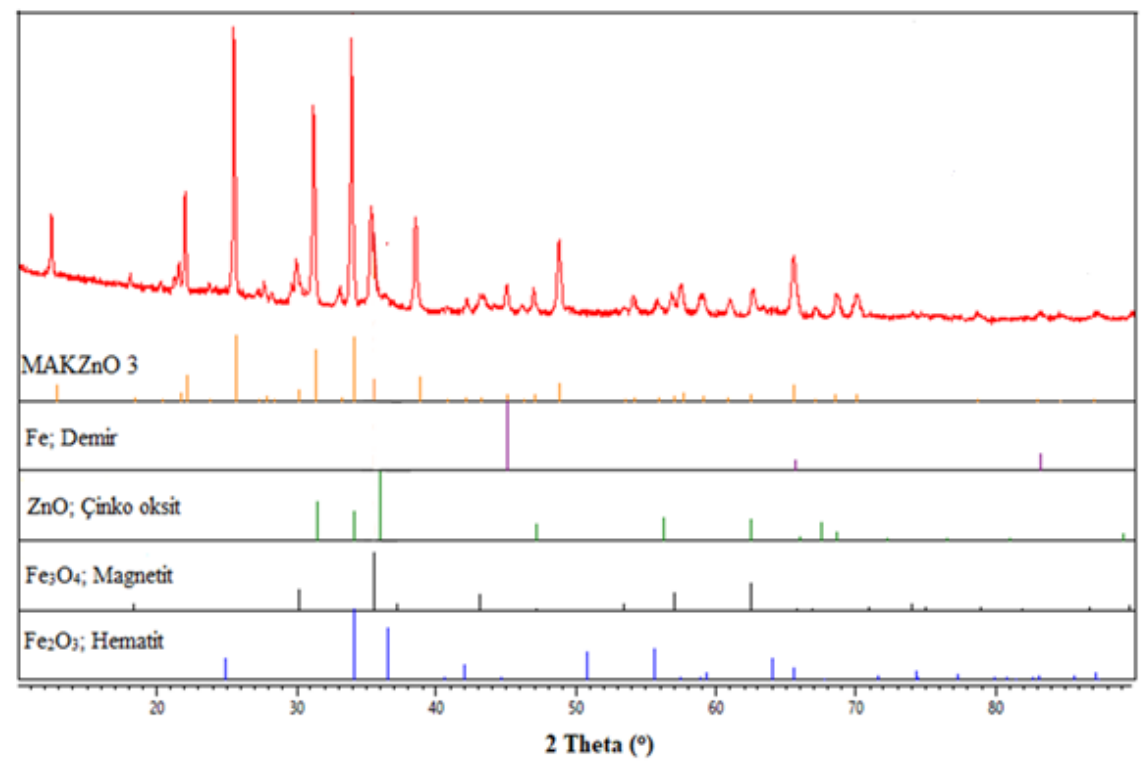

Şekil 9. MAKZnO 3 XRD spektrumu

MAKZnO 4, $\mathrm{ZnCl}_{2}$ yerine $\mathrm{Zn}\left(\mathrm{NO}_{3}\right)_{2} \cdot 6 \mathrm{H}_{2} \mathrm{O}$ kullanılarak üretilen kompozitin XRD spektrumu Şekil 10'da verilmiştir. $\mathrm{ZnCl}{ }_{2}$ ile üretilen kompozitlerin hepsinde $\mathrm{Fe}_{2} \mathrm{O}_{3}$ (Hematit) elde edilmiştir. Ancak $\mathrm{Zn}\left(\mathrm{NO}_{3}\right)_{2} \cdot 6 \mathrm{H}_{2} \mathrm{O}$ ile üretilen $\mathrm{MAKZnO} 4$ 'de $\mathrm{Fe} 2 \mathrm{O}_{3}$ oluşmamıştır. MAKZnO 4 kompozittinde; $2 \theta=35.5^{\circ}$ 'deki $\mathrm{Fe}_{3} \mathrm{O}_{4}$ pikinin hesaplanan ortalama kristal boyutu $37.83 \mathrm{~nm}$ 'dir. $2 \theta=$ $31.5^{\circ}$ 'deki $\mathrm{ZnO}$ pikinin ise ortalama kristal boyutu $56.23 \mathrm{~nm}$ olarak bulunmuştur.

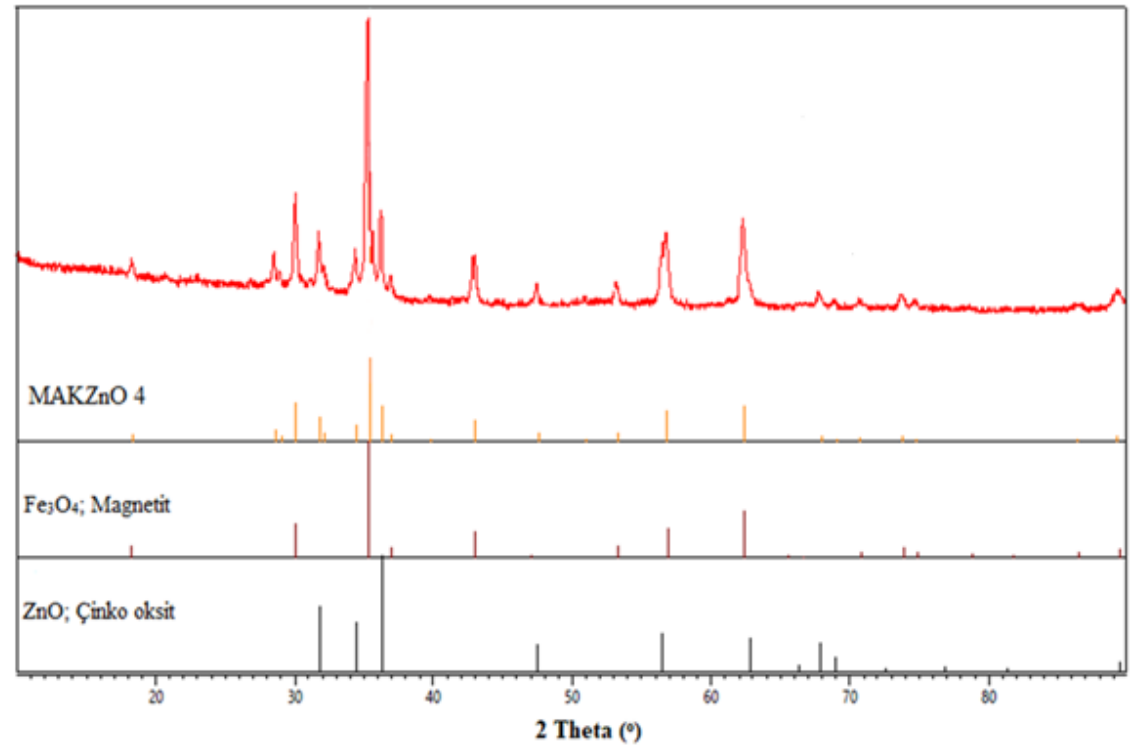

Şekil 10. MAKZnO 4 XRD spektrumu

Şekil 11'de MAKZnO 3'e göre; ZnCl 'nin iki katı kullanılarak üretilen MAKZnO 5'in XRD spektrumu görülmektedir. MAKZnO 5'de de $\mathrm{Fe}_{3} \mathrm{O}_{4}$ (Magnetit), $\mathrm{Fe}_{2} \mathrm{O}_{3}$ (Hematit), $\mathrm{ZnO}$ kristalleri ve metalik Fe olduğu XRD piklerinde görülmüştür. MAKZnO 5'deki $\mathrm{ZnO}$ (100), $\mathrm{Fe}_{3} \mathrm{O}_{4}$ (311) ve $\mathrm{Fe}_{2} \mathrm{O}_{3}$ 'ün (012) hesaplanan ortalama kristal boyutları sirasiyla, 42.13, 42.58 ve 55.46 nm olarak bulunmuştur. 


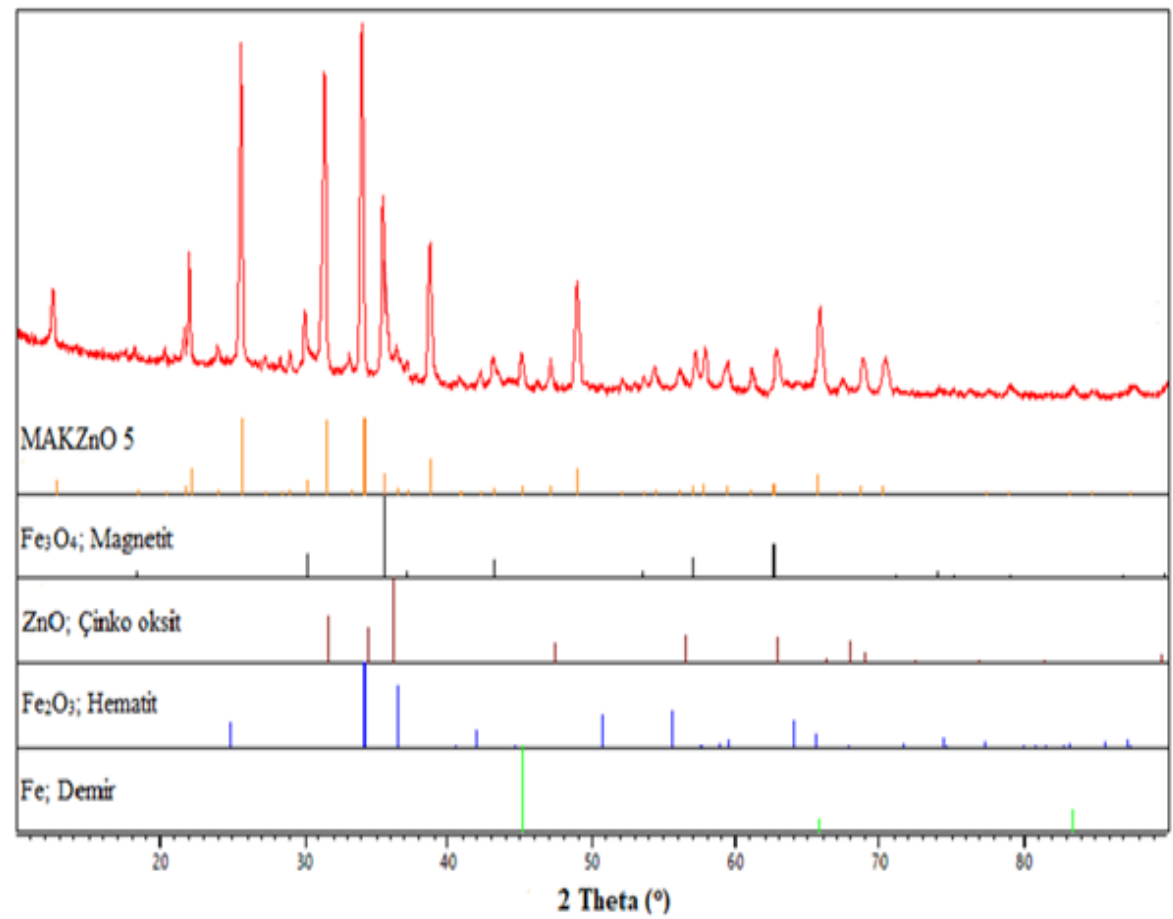

Şekil 11. MAKZnO 5 XRD spektrumu

\subsection{Adsorpsiyon Dengesi}

Üretilen MAKZnO 1-5 numunelerinin farklı miktarlarda (2-10 mg) ve $50 \mathrm{ml}$ MG boya çözeltisinde adsorpsiyon deneyleri gerçekleştirilmiştir. Bu deneylerde zamana karşı $(\mathrm{t})$ adsorplanan boya (q) miktarlarından elde edilen denge verileri Langmuir (Langmuir, 1916) ve Freundlich (Freundlich, 1926) modellerine uygulanmıştır ve Ek-1 (Şekil 12-21)'de grafikleri verilmiştir. Elde edilen grafiklerin verilerinden hesaplanan $Q_{0}$ değerleri sırası ile $173 \mathrm{mg} / \mathrm{g}, 448 \mathrm{mg} / \mathrm{g}, 502.5 \mathrm{mg} / \mathrm{g}, 427.4 \mathrm{mg} / \mathrm{g}, 458.7 \mathrm{mg} / \mathrm{g}$ olarak bulunmuştur. MAKZnO 3'ün en yüksek $\mathrm{Q}_{0}$ değerine sahip olduğu tespit edilmiştir. Tablo 2‘de verilen model parametreleri ve $\mathrm{R}^{2}$ değerleri incelendiğinde hem Freundlich hem Langmuir için uyumlu olduğunu göstermiştir.

Tablo 2. Langmuir ve Freundlich model parametreleri.

\begin{tabular}{|c|c|c|c|c|c|}
\hline Modeller & MAKZnO 1 & MAKZnO 2 & MAKZnO 3 & MAKZnO 4 & MAKZnO 5 \\
\hline $\begin{array}{l}\text { Langmuir } \\
\mathrm{q}_{\mathrm{e}}=\frac{\mathrm{Q}_{\mathrm{o}} \mathrm{bC}_{\mathrm{e}}}{1+\mathrm{bC}_{\mathrm{e}}}\end{array}$ & $\begin{array}{l}\mathrm{Q}_{0}: 173 \mathrm{mg} / \mathrm{g} \\
\mathrm{b}: 0.33 \\
\mathrm{R}^{2}: 0.81\end{array}$ & $\begin{array}{l}\mathrm{Q}_{0}: 448 \mathrm{mg} / \mathrm{g} \\
\text { b: } 0.011 \\
\mathrm{R}^{2}: 0.90\end{array}$ & $\begin{array}{l}\mathrm{Q}_{0}: 502.5 \mathrm{mg} / \mathrm{g} \\
\mathrm{b}: 0.096 \\
\mathrm{R}^{2}: 0.80\end{array}$ & $\begin{array}{l}\mathrm{Q}_{0}: 427.4 \mathrm{mg} / \mathrm{g} \\
\text { b: } 0.11 \\
\mathrm{R}^{2}: 0.90\end{array}$ & $\begin{array}{l}\mathrm{Q}_{0}: 458.7 \mathrm{mg} / \mathrm{g} \\
\mathrm{b}: 0.12 \\
\mathrm{R}^{2}: 0.92\end{array}$ \\
\hline $\mathrm{q}_{\mathrm{e}}=K_{f} \mathrm{C}_{\mathrm{e}}^{1 / \mathrm{n}}$ & $\begin{array}{l}\mathrm{K}_{\mathrm{f}}: 47.8 \\
1 / \mathrm{n}: 0.50 \\
\mathrm{R}^{2}: 0.86\end{array}$ & $\begin{array}{l}\mathrm{K}_{\mathrm{f}}: 47.8 \\
1 / \mathrm{n}: 0.76 \\
\mathrm{R}^{2}: 0.90\end{array}$ & $\begin{array}{l}\mathrm{K}_{\mathrm{f}}: 45.2 \\
1 / \mathrm{n}: 0.82 \\
\mathrm{R}^{2}: 0.65\end{array}$ & $\begin{array}{l}\mathrm{K}_{\mathrm{f}}: 47.3 \\
1 / \mathrm{n}: 0.75 \\
\mathrm{R}^{2}: 0.93\end{array}$ & $\begin{array}{l}\mathrm{K}_{\mathrm{f}}: 56.4 \\
1 / \mathrm{n}: 0.68 \\
\mathrm{R}^{2}: 0.94\end{array}$ \\
\hline
\end{tabular}

\subsection{Adsorpsiyon Kinetiği}

Şekil 22 ve Şekil 23'de MAK/ZnO - MG adsorpsiyon sistemlerinin Lagergren yalancı-birinci ve ikinci derece hız sabitlerinin elde edilmesi için zamana karşı $\log \left(\mathrm{q}_{\mathrm{e}}-\mathrm{q}\right)$ ve $1 /\left(\mathrm{q}_{\mathrm{e}}-\mathrm{q}\right)$ değerlerinin değişimleri verilmiştir (Ho ve McKay, 1999; Lagergren, 1898). 


\section{Avrupa Bilim ve Teknoloji Dergisi}

$\mathrm{Bu}$ grafiklerdeki doğruların eğiminden ve kesim noktasından yararlanarak $\mathrm{k}_{1}, \mathrm{k}_{2}$ ve korelasyon katsayıları karesi $\left(\mathrm{R}^{2}\right)$ değerleri bulunmuştur. Tablo 3 'de verilmiştir. $\mathrm{k}_{1}, \mathrm{k}_{2}$ hız sabitlerinin $\mathrm{R}^{2}$ değerleri karşılaştırıldığında, birinci derece için $\mathrm{R}^{2}$ değerlerinin tüm ortamlar için daha yüksek olduğu bulunmuştur. Bu sonuçlara göre boyar maddenin MAK/ZnO üzerine adsorpsiyonu üzerine tutunmanın fiziksel adsorpsiyon ile gerçekleştiğini desteklemektedir (Zheng ve ark., 2019).

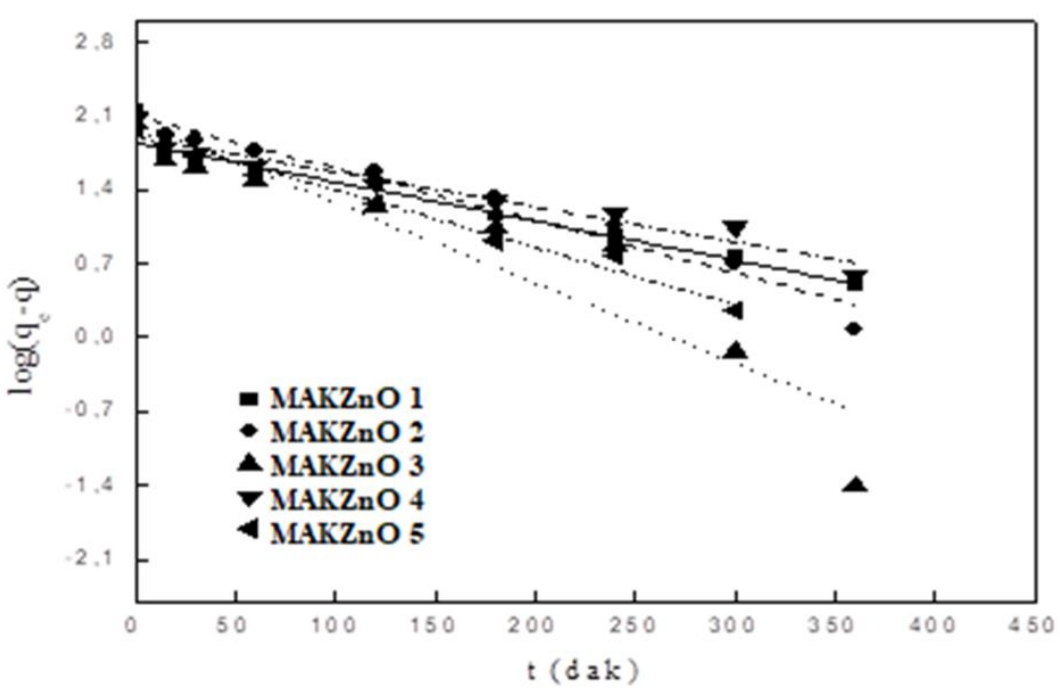

Şekil 22. Birinici derece kinetik ĕgrileri ( $\left.m_{a d s}: 0.12 \mathrm{~g} / \mathrm{L}\right)$.

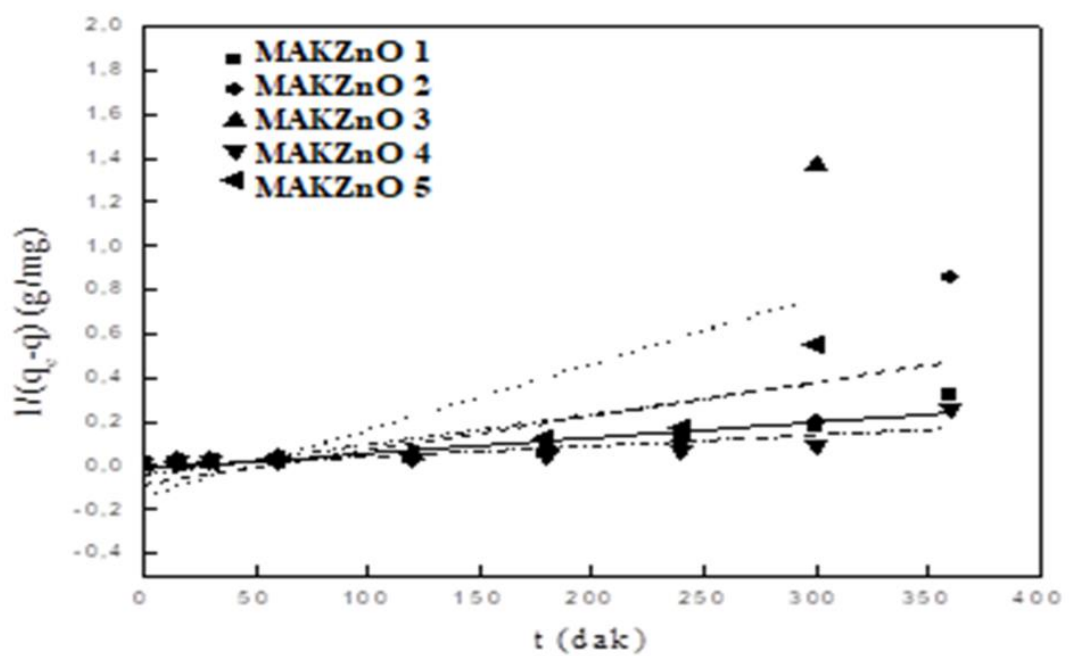

Şekil 23. İkinci derece kinetik ĕgrileri ( $\left.m_{\text {ads }}: 0.12 \mathrm{~g} / \mathrm{L}\right)$.

Tablo 3. Birinci ve ikinci derece kinetik parametreleri $\left(m_{a d s}: 0.12 \mathrm{~g} / \mathrm{L}\right)$

\begin{tabular}{c|c|c|c|c|c}
\hline Adsorbentler & MAKZnO 1 & MAKZnO 2 & MAKZnO 3 & MAKZnO 4 & MAKZnO 5 \\
\hline $\boldsymbol{k}_{\boldsymbol{l}}\left(\right.$ dak $\left.^{-1}\right)$ & 0.009 & 0.011 & 0.018 & 0.008 & 0.012 \\
\hline $\boldsymbol{R}^{2}$ & 0.97 & 0.92 & 0.72 & 0.88 & 0.94 \\
\hline $\boldsymbol{k}_{2}(\boldsymbol{g} /$ mg.dak) & $7 \times 10^{-4}$ & 0.0015 & 0.003 & $5 \times 10^{-4}$ & 0.014 \\
\hline $\boldsymbol{R}^{2}$ & 0.66 & 0.25 & 0.19 & 0.45 & 0.47 \\
\hline \hline
\end{tabular}




\section{European Journal of Science and Technology}

\section{Sonuç}

$\mathrm{Bu}$ çalışmada, MAKZnO nanokompozitleri, tek basamakta kimyasal aktivasyon ve termal yöntemler kullanılarak atık kauçuktan üretilmiş̧ir. MAKZnO 1-5 nanokompozitlerin yüzey özellikleri ve morfolojik özellikleri belirlenmiştir. MAKZnO nanokompozitleri MG adsorpsiyonu için elde edilen deneysel denge verileri Langmuir ve Freundlich izoterm modellerine uygulanmıştır. En yüksek adsorpsiyon kapasitesi $502.5 \mathrm{mg} / \mathrm{g}$ ile MAKZnO 3 nanokompozitinde bulunmuştur. Ayrıca MAKZnO 15 nanokompozitlerine Lagergren'in birinci ve sözde ikinci dereceli kinetik modelleri uygulanmıştır. Birinci ve ikinci derece kinetik modellerine ait $\mathrm{R}^{2}$ değerleri incelendiğinde, $25^{\circ} \mathrm{C}$ için MG'nin MAKZnO nanokompozit yüzeyler üzerine adsorpsiyon hızının birinci derece kinetik modeli ile daha iyi uyum sağladığı bulunmuştur. Bu durum MG moleküllerinin MAKZnO üzerine tutunmasının fiziksel adsorpsiyon ile gerçekleştiğini desteklemektedir.

\section{Teşekkür}

Bu çalışma Zonguldak Bülent Ecevit Üniversitesi Bilimsel Araştırma Projeleri Birimi (proje no: 2018-52349806-01) tarafindan desteklenmiştir.

\section{Kaynakça}

Akkurt, F., Benli, S., Alicilar, A. (2005). Dispers Kirmizi 1 Tekstil Boyasinin Karakterizasyonu Ve Uygulanabilirliğinin Araştirilmasi. Gazi Üniversitesi Mühendislik-Mimarlık Fakültesi Dergisi, 20(4).

Aluigi, A., Rombaldoni, F., Tonetti, C., Jannoke, L. (2014). Study of Methylene Blue adsorption on keratin nanofibrous membranes. Journal of hazardous materials, 268, 156-165.

Chaki, S., Malek, T. J., Chaudhary, M., Tailor, J., Deshpande, M. (2015). Magnetite Fe3O4 nanoparticles synthesis by wet chemical reduction and their characterization. Advances in Natural Sciences: Nanoscience and Nanotechnology, 6(3), 035009.

Do, M. H., Phan, N. H., Nguyen, T. D., Pham, T. T. S., Nguyen, V. K., Vu, T. T. T., Nguyen, T. K. P. (2011). Activated carbon/Fe $\mathrm{O}_{4}$ nanoparticle composite: Fabrication, methyl orange removal and regeneration by hydrogen peroxide. Chemosphere, 85(8), $1269-1276$.

Erdoğan, F. O. (2017) Düşük Maliyetli Adsorbentler Üzerine Dispers Sarı 211 Tekstil Boyasının Adsorpsiyonu. Afyon Kocatepe Üniversitesi Fen ve Mühendislik Bilimleri Dergisi, 17(3), 889-898.

Freundlich, H. (1926). Colloid \& capillary chemistry: Methuen \& co. ltd.

Fuertes, A. B., Tartaj, P. (2006). A facile route for the preparation of superparamagnetic porous carbons. Chemistry of Materials, 18(6), 1675-1679.

Ho, Y.-S., McKay, G. (1999). Pseudo-second order model for sorption processes. Process biochemistry, 34(5), 451-465.

Kopac, T., Sulu, E., Toprak, A. (2016). Effect of KOH treatment on bituminous coal for the effective removal of Basic Blue 41 dye from aqueous solutions. Desalination and Water Treatment, 57(59), 29007-29018.

Kopac, T., Toprak, A. (2007). Preparation of activated carbons from Zonguldak region coals by physical and chemical activations for hydrogen sorption. International Journal of Hydrogen Energy, 32(18), 5005-5014.

Lagergren, S. (1898). Zur theorie der sogenannten adsorption geloster stoffe. Kungliga svenska vetenskapsakademiens. Handlingar, 24, 1-39.

Langmuir, I. (1916). The constitution and fundamental properties of solids and liquids. Part I. Solids. Journal of the American chemical society, 38(11), 2221-2295.

Toprak, A., Bozgeyik, K. Examination of the Effects of Activated Carbon Produced from Coal Using Single-Step $\mathrm{H}_{3} \mathrm{PO}_{4} / \mathrm{N}_{2}+\mathrm{H}_{2} \mathrm{O}$ Vapor Activation on the Adsorption of Bovine Serum Albumin at Different Temperatures and $\mathrm{pH}$ Values. Journal of the Turkish Chemical Society, Section A: Chemistry, 5(1), 219-236.

Wang, D.-W., Li, F., Lu, G. Q., Cheng, H.-M. (2008). Synthesis and dye separation performance of ferromagnetic hierarchical porous carbon. Carbon, 46(12), 1593-1599.

Yang, N., Zhu, S., Zhang, D., Xu, S. (2008). Synthesis and properties of magnetic $\mathrm{Fe}_{3} \mathrm{O}_{4}$-activated carbon nanocomposite particles for dye removal. Materials Letters, 62(4-5), 645-647.

Yener, J., Kopac, T., Dogu, G., Dogu, T. (2006). Adsorption of Basic Yellow 28 from aqueous solutions with clinoptilolite and amberlite. Journal of Colloid and Interface Science, 294(2), 255-264.

Zheng, X., Feng, S., Wang, X., Shi, Z., Mao, Y., Zhao, Q., Wang, S. (2019). MSNCs and MgO-MSNCs as drug delivery systems to control the adsorption kinetics and release rate of indometacin. Asian Journal of Pharmaceutical Sciences, 14(3), 275-286. 